Jurnal Penelitian Pendidikan Geografi Volume 4 No. 1 Januari 2019

\title{
DESKRIPSI MINAT IBU-IBU PASANGAN USIA SUBUR (PUS) PENGGUNA KONTRASEPSI DI KELURAHAN ANGGALOMELAI KECAMATAN ABELI KOTA KENDARI SULAWESI TENGGARA
}

\author{
Sri Rezqyawati ${ }^{1}$ \\ ${ }^{1}$ Alumni Pendidikaan Geografi Universitas Halu Oleo
}

\begin{abstract}
Abstrak: Penelitian ini bertujuan untuk menjelaskan Bagaimana minat ibu-ibu Pasangan Usia Subur pengguna kontrasepsi dengan metode MKJP dan non-MKJP. Penelitian ini dilakukan di Kelurahan Anggalomelai Kecamatan Abeli Kota Kendari Sulawesi Tenggara dengan jumlah sampel sebanyak 41 informan. Metode penelitian menggunakan metode kualitatif. Peneliti mengambil data dengan teknik wawancara dan studi dokumentasi. Pemilihan sampel dengan menggunakan teknik purposive sampling yaitu teknik penentuan sampel dengan pertimbangan tertentu. Hasil penelitian ini menunjukan bahwa minat ibu-ibu Pasangan Usia Subur dalam menggunakan alat kontrasepsi/KB dengan metode MKJP yaitu implan, Intra Uterine Device/spiral dan Metode Operasi Wanita/tubektomi sebanyak 14.79\%. Alasan ketertarikan PUS memilih metode MKJP karena efektifitas untuk menunda dan menghentikan kehamilan, perasaan nyaman dan cocok terhadap alat kontrasepsi/KB, manfaat yang dirasakan serta dukungan dari suami dan pelayanan kesehatan, sedangkan minat untuk ibu-ibu PUS dalam menggunakan alat kontrasepsi/KB dengan memilih metode non-MKJP yaitu suntik, kondom dan pil sebanyak 56.21\%. Alasan ketertarikan PUS memilih metode non-MKJP karena rasa takut PUS untuk memasang alat kontrasepsi/KB dengan metode MKJP, perasaan nyaman dan cocok karena manfaat lain yang diberikan alat kontrasepsi dan kurangnya efek samping yang negatif serta dukungan dari luar seperti palayanan kesehatan dalam mengontrol akseptor KB.
\end{abstract}

Kata Kunci: Minat, PUS, Alat kontrasepsi/KB. 
Jurnal Penelitian Pendidikan Geografi Volume 4 No. 1 Januari 2019

\title{
DESCRIPTIONS OF THE INTEREST OF CONTRACEPTION USERS OF FERTILE AGE COUPLES (PUS) IN ANGGALOMELAI VILLAGE, ABELI DISTRICT, KENDARI CITY
}

\author{
Sri Rezqyawati ${ }^{1}$ \\ ${ }^{1}$ Geography Educational Alumni Halu Oleo University
}

\begin{abstract}
Abtract: This research was conducted in Anggalomelai Village, Abeli Subdistrict, Kendari City, Southeast Sulawesi with a total sample of 41 informants. The research method uses qualitative methods. Researchers take data with interview techniques and documentation studies. Selection of samples using purposive sampling technique is the technique of determining samples with certain considerations. The results of this study indicate that the interest of mothers of fertile age couples in using contraceptives / contraception with the MKJP method is implant, intra-uterine device / spiral and female surgery / tubectomy method as much as $14.79 \%$. Reasons for EFA interest in choosing MKJP method because of its effectiveness in delaying and stopping pregnancy, feeling comfortable and suitable for contraception / family planning, perceived benefits and support from husband and health services, while interest for PUS mothers in using contraception / family planning by choosing nonMKJP methods are injections, condoms and pills as much as $56.21 \%$. The reason for PUS's interest in choosing non-MKJP method because of fear of EFA to install contraception / contraception with the MKJP method, feeling comfortable and suitable because of other benefits given contraception and lack of negative side effects and external support such as health services in controlling family planning acceptors.
\end{abstract}

Keywords: Interests, EFA, contraception / family planning.

\section{PENDAHULUAN}

Indonesia merupakan salah satu negara berkembang dengan berbagai jenis masalah. Secara garis besar masalah pokok yang dihadapi Indonesia dibidang kependudukan adalah jumlah pertumbuhan penduduk yang besar dengan laju pertumbuhan penduduk yang relatif masih tinggi, persebaran penduduk yang tidak merata, struktur umur muda, dan kualitas penduduk yang masih harus ditingkatkan. (Winjosastro, 1999 dalam Purba, 2009). Keadaan penduduk yang demikian telah mempersulit usaha peningkatan dan pemerataan kesejahteraan rakyat. Oleh karena itu pemerintah terus berupaya untuk menekan laju pertumbuhan penduduk. Salah satu upaya untuk dapat menangani permasalahan tersebut dengan melalui kontrol terhadap program keluarga berencana. Program Keluarga Berencana (KB) merupakan salah satu upaya dalam mengendalikan dan menurunkan laju pertumbuhan penduduk dengan cara meningkatkan pengguna kontrasepsi.

Kontrasepsi merupakan salah satu upaya untuk mencegah terjadinya kehamilan. Upaya ini dapat bersifat sementara dapat pula bersifat permanen. Metode kontrasepsi di Indonesia berdasarkan keefektifannya terbagi menjadi dua macam yaitu 
Jurnal Penelitian Pendidikan Geografi Volume 4 No. 1 Januari 2019

Metode Kontrasepsi Jangka Panjang (MKJP) dan Metode Kontrasepsi Jangka Pendek (non-MKJP). Alat kontrasepsi dengan MKJP meliputi Intra Uterine Device/spiral, Implan/susuk, Metode Operasi Wanita/tubektomi dan Metode Operasi Pria/vasektomi dan Alat kontrasepsi dengan non-MKJP meliputi Suntik, Pil, Kondom dan metode-metode lain yang tidak termasuk dalam Metode Kontrasepsi Jangka Panjang.

Usia 15-49 tahun merupakan usia subur bagi seorang perempuan karena pada rentang usia tersebut memungkinkan perempuan melahirkan anak cukup besar. Semakin banyak jumlah Pasangan Usia Subur (PUS) maka peluang banyaknya anak yang dilahirkan juga semakin besar. Dengan demikian pembatasan jumlah anak perlu diperhatikan agar tercapai keluarga yang sejahtera. Salah satu cara untuk menekan laju pertumbuhan penduduk adalah melalui program KB.

Program keluarga berencana akan sukses jika setiap pasangan usia subur ikut serta dalam pelaksanaan program tersebut. Keikutsertaan calon akseptor terhadap penggunaan aalat kontrasepsi dapat memberikan dampak positif bagi tujuan program keluarga berencana. Terlibatnya pasangan usia subur menjadi akseptor KB didorong dengan adanya minat terhadap alat kontrasepsi, secara tidak langsung minat juga menjadi faktor penting dalam suksesnya pelaksanaan program $\mathrm{KB}$, oleh karena itu perlu adanya perhatian khusus terhadap pasangan usia subur agar selalu konsisten untuk menggunakan alat kontrasepsi/KB baik dengan metode jangka panjang ataupun yang jangka pendek.

Kecamatan Abeli dengan jumlah penduduk pada tahun 2011 sebanyak 23.312 jiwa, meningkat pada tahun 2012 sebanyk 23.719 jiwa, kemudian meningkat pada tahun 2013 sebanyak 24.125 jiwa, tahun 2014 sebanyak 24.532 jiwa dan meningkat lagi pada tahun 2015 sebanyak 24.939 jiwa. (Pokja Sanitasi Kota Kendari, 2011), dari data tersebut terlihat bahwa jumlah penduduk Kecamatan Abeli 5 tahun terakhir mengalami peningkatan sehingga perlu dikontrol melalui program Keluarga Berencana (KB) dengan meningkatkan akseptor KB aktif.

Dari data observasi awal yang diperoleh dari Pusat Kesehatan Masyarakat Abeli, di Kelurahan Anggalomelai dengan jumlah kepala keluarga sebanyak 467 KK, dan jumlah Pasangan Usia Subur sebanyak 338 PUS dengan pengguna alat kontrasepsi 240 akseptor, (Profil Puskesmas Abeli, 2015)). Kelurahan Anggalomelai merupakan salah satu Kelurahan di Kota kendari yang menjadi sasaran pemerintah dalam menjalankan program Keluarga Berencana yaitu program kampung $\mathrm{KB}$ untuk mengontrol pertumbuhan penduduk. Dengan adanya kegiatan atau program tersebut dapat menjadi acuan bagi pemerintah untuk melihat sejauh mana ketertarikan ibu-ibu pasangan usia subur dalam menggunakan alat kontrasepsi/KB dengan dua metode yang diterapkan yaitu Metode Kontrasepsi Jangka Panjang (MKJP) dan non-MKJP.

Minat pada dasarnya adalah penerimaan akan suatu hubungan antara diri sendiri dengan sesuatu diluar diri. Semakin kuat atau semakin dekat hubungan tersebut,semakin besar pula minatnya (Djaali, 2013:121). Crow \& Crow dalam Djaali (2013:121) bahwa minat berhubungan dengan gaya gerak yang mendorong seseorang untuk menghadapi atau berurusan dengan 
orang, benda, kegiatan, pengalaman yang dirangsang oleh keinginan itu sendiri. Minat adalah suatu keadaan dimana seseorang mempunyai perhatian terhadap sesuatu dan disertai keinginan untuk mengetahui dan mempelajari maupun membuktikan lebih lanjut Bimo Walgito (1981:38).

Defenisi Pasangan Usia Subur (PUS) adalah pasangan suami isteri yang masi berpotensi untuk mempunyai keturunan atau di tandai dengan belum datangnya waktu monopaus peserta Keluarga Berencana adalah pasangan usia subur di mana salah satu orang menggunakan cara /alat kontrasepsi untuk tujuan mencegah kehamilan baik mulai program maupun non program. Pasangan Usia Subur adalah pasangan yang isterinya berumur 15-49 tahun atau pasangan suami isteri yang kurang dari 15 tahun dan sudah mensteruasi atau isteri berumur lebih dari 50 tahun tetapi belum monopaus (BKKBN, 2009). Pasangan usia subur yang di maksud adalah mereka yang telah terikat pernikahan secara agama dan bersesuaian dengan peraturan perundang-undangan pernikahan yang menurut hukum yang berlaku di Indonesia.

Kontrasepsi berasal dari kata kontra yang berarti mencegah atau melawan sedangkan konsepsi adalah pertemuan antara sel telur yang matang dan sel sperma yang mengakibatkan kehamilan, maksud dari kontrasepsi adalah menghindari atau mencegah terjadinya kehamilan sebagai akibat pertemuan antara sel telur matang dengan sel sperma tersebut (BKKBN, 2009). Kontrasepsi adalah upaya mencegah terjadinya kehamilan (Maimunah, 2005).

\section{METODE PENELITIAN Lokasi Penelitian}

Lokasi penelitian adalah objek penelitian dimana kegiatan penelitian itu dilakukan. Penentuan lokasi dimaksudkan untuk mempermudah danmemperjelas objek yang menjadi sasaran penelitian, sehingga permasalahan tidak meluas.Penelitian ini telah dilakukan di Kelurahan Anggalomelai Kecamatan Abeli Kota Kendari Sulawesi Tenggara. Waktu penelitian ini dilaksanakan pada bulan Mei 2018.

\section{Jenis Penelitian}

Jenis penelitian ini adalah penelitian kualtitatif deskriptif,dengan pendekatan studi kasus (case study). Pendekatan studi kasus merupakan suatu metode penyelidikan secara langsung dengan latar yang alamiah dan memusatkan perhatian pada suatu peristiwa secara intensif dan rinci.

\section{Penentuan Informan}

Informan penelitian yaitu dipilih secara purposive sampling yaitu teknik penarikan sampel sercara subjektif dengan maksud atau tujuan tertentu, yang mana mengenggap bahwa informan yang diambil tersebut memiliki informasi yang diperlukan bagi siapa saja dan peneliti yang menurut Ferdinad (2006:195) purposive sampling adalah penentuan sampel dimana peneliti memiliki sampel secara subjektif. Metode pengambilan sampel dalam penelitian ini adalah purposive sampling yakni teknik pemilihan informasi yang dilakukan serta dipilih berdasarkan pertimbangan tertentu, oleh karena itu sampel di tentukan dengan purposive (sengaja) sehingga sampel penelitian tidak perlu mewakili populasi, tetapi lebih kepada kemampuan sampel (informan) untuk memberikan 
informasi selengkap mungkin kepada peneliti. Peneliti melakukan wawancara dengan Ibu Fatimah selaku bidan yang menangani ibu-ibu yang menggunakan alat kontasepsi/KB dan 41 informan ibu-ibu PUS yang menggunakan alat kontrasepsi.

Instrumen Penelitian

Instrumen penelitian adalah alat atau bahan yang akan di gunakan untuk pengumpulan data. Alat atau bahan yang digunakan atau di butuhkan dalam penelitian ini adalah sebagai berikut:

a. Daftar pertanyaan yang menjadi pedoman wawancara kepada informan yaitu istri petani yang bekerja di sektor publik dan informan lain yang terkait dengan penelitian ini.

b. Kamera sebagai alat dokumentasi dan alat rekam untuk wawancara kepada informan.

Jenis dan Sumber Data

Dalam penelitian ini data yang digunakan meliputi dua jenis data, yaitu data primer dan data sekunder.
Teknik Pengumpulan Data

Dalam usaha untuk pengumpulan data dalam penelitian ini, peneliti menggunakan cara sebagai berikut:
a. Observasi
b. Wawancara
c. Dokumentasi

\section{HASIL PENELITIAN}

Gambaran Minat Ibu-Ibu Pasangan Usia Subur Yang Menggunakan Alat Kontrasepsi/KB Dengan Metode Kontrasepsi Jangka Panjang (MKJP)

Untuk mengetahui bagaimana minat ibu-ibu pasangan usia subur di Kelurahan Anggalomelai dalam menngunakan alat kontrasepsi/KB dengan metode kontrasepsi jangka panjang seperti implan, Intra Uterine Device, dan Metode Operasi wanita dapat dilihat pada tabel dibawah ini:

Tabel 3.3 Gambaran Minat Ibu-Ibu PUS Yang Memilih Alat Kontrasepsi Dengan Metode MKJP

\begin{tabular}{|c|c|c|c|c|c|c|}
\hline \multirow[b]{2}{*}{ No } & \multirow[b]{2}{*}{ RW } & \multirow{2}{*}{$\begin{array}{l}\text { Jumlah } \\
\text { Pasangan } \\
\text { Usia } \\
\text { Subur }\end{array}$} & \multicolumn{3}{|c|}{ Alat Kontrasepsi/KB } & \multirow[b]{2}{*}{$\begin{array}{l}\text { Persentase } \\
(\%)\end{array}$} \\
\hline & & & $\begin{array}{l}\text { Metode } \\
\text { Operasi } \\
\text { Wanita } \\
\text { (tubektomi) }\end{array}$ & $\begin{array}{l}\text { Intra } \\
\text { Uterine } \\
\text { Device } \\
\text { (spiral) } \\
\end{array}$ & $\begin{array}{l}\text { Implan } \\
\text { (susuk) }\end{array}$ & \\
\hline 1. & RW.I & 74 & 1 & 2 & 7 & $13.51 \%$ \\
\hline 2. & RW.II & 71 & 2 & 1 & 9 & $16.90 \%$ \\
\hline 3. & RW.III & 64 & 1 & 1 & 5 & $10.93 \%$ \\
\hline 4. & RW.IV & 62 & 0 & 1 & 10 & $17.74 \%$ \\
\hline 5. & RW.V & 67 & 1 & 2 & 7 & $14.92 \%$ \\
\hline \multicolumn{2}{|c|}{ Jumlah } & 338 & 5 & 7 & 38 & $14.79 \%$ \\
\hline
\end{tabular}

Sumber: Hasil observasi dan wawancara

Dari hasil wawancara diatas dapat diketahui bahwa Pasangan Usia Suburmemiliki minat yangberbeda

pada ketiga jenis $\mathrm{KB}$ yang digunakan seperti KB Implan, Intra Uterine Device dan Metode Operasi Wanita 
terlihat dari banyaknya jumlah akseptor yang menggunakan alat kontrasepsi/KB tersebut, di RW.I dengan jumlah PUS sebanyak 74 orang dengan akseptor KB Metode Operasi Wanita, Intra Uterine Device, danImplan sebanyak $13.51 \%$, di RW.II dengan jumlah PUS sebanyak 71 orang dengan akseptor KB Metode Operasi Wanita, IUD, dan Implan sebanyak $16.90 \%$, di RW.III dengan jumlah PUS 64 orang dengan akseptor KB MOW, IUD, dan Implan sebanyak $10.93 \%$, di RW.IV dengan jumlah PUS 62 orang dengan akseptor KB Metode Operasi Wanita, Intra Uterine Device, dan Implan $17.74 \%$, di RW.V dengan jumlah PUS 67 orang dengan akseptor KB Metode Operasi Wanita, Intra Uterine $14.79 \%$

\section{Gambaran Minat ibu-ibu Pasangan Usia Subur yang menggunakanAlat Kontrasepsi/KB dengan Metode Kontrasepsi Jangka Pendek (non- MKJP)}

Untuk gambaran bagaimana minat ibu-ibu Pasangan usia subur di Kelurahan Anggalomelai terhadap penggunaan alat kontrasepsi/KB dengan metode kontrasepsi jangka pendek seperti suntik, kondom, dan pil dapat dilihat pada tabel dibawah ini:

Tabel 3.4 Gambaran minat ibu-ibu PUS yang menggunakan Alat Kontrasepsi /KB dengan metode non-MKJP.

\begin{tabular}{lllllll}
\hline & & Jumlah & \multicolumn{2}{l}{ Alat Kontrasepsi/KB } & \\
\cline { 7 - 7 } No & Rukun & Pasangan & & & & Persentase \\
& Warga & Usia Subur & Suntik & Kondom & Pil & $(\%)$ \\
\hline 1. & RW. I & 74 & 23 & 0 & 19 & $56.75 \%$ \\
2. & RW.II & 74 & 18 & 1 & 20 & $52.70 \%$ \\
3. & RW. III & 64 & 16 & 0 & 16 & $50 \%$ \\
4. & RW. IV & 62 & 19 & 0 & 18 & $59.67 \%$ \\
5. & RW. V & 67 & 19 & 1 & 20 & $59.70 \%$ \\
\hline Jumlah & 338 & 95 & 2 & 93 & $56.21 \%$ \\
\hline
\end{tabular}

Sumber: Hasil observasi dan wawancara (2018)

Dari data diatas menunjukan adanya perbedaan minat pada setiap Pasangan Usia Subur dalam memilih alat kontrasepsi/KB yang digunakan terlihat dari banyaknya jumlah akseptor yang berminat menggunakan, di RW.I dengan jumlah Pasangan Usia Subur 74 orang dengan akseptor KBsuntikdan pil sebanyak $56.75 \%$,di RW.II dengan jumlah PUS 71 orang dengan akseptor KB suntik, kondom dan pil sebanyak $52.70 \%$, di RW.III dengan jumlah PUS 64 orang dengan akseptor KB suntik dan pil sebanyak $50 \%$, di RW.IV dengan jumlah PUS 62 orang dengan akseptor $\mathrm{KB}$ suntik dan pil sebanyak $59.67 \%$, di RW.V dengan jumlah PUS 67 orang dengan akseptor KB suntik, kondom dan pil sebanyak 59.70\%.

\section{PEMBAHASAN}

Minat merupakan aspek psikis yang dimiliki seseorang yang menimbulkan rasa suka atau tertarik terhadap sesuatu dan mampu mempengaruhi tindakan orang tersebut. Minat mempunyai hubungan yang erat dengan dorongan dalam diri individu yang kemudian menimbulkan keinginan untuk berpartisipasi atau terlibat pada suatu yang diminatinya, 
baik itu minat pada individu lain, suatu benda, makanan atau minuman dan sebagainya dalam rangka pemenuhan kebutuhan. Minat pada setiap individu muncul disebkan oleh pembawaan dari individu itu sendiri atau dari lingkungan individu tersebut, seperti halnya minat dalam menggunakan alat kontrasepsi/KB pada setiap individu memiliki keinginan yang berbeda dalam memilih metode kontrasepsi/KB yang akan digunakan baik itu denganMetode Kontrasepsi Jangka Panjang (MKJP) seperti Metode Operasi Wanita (tubektomi), Intra Uterin Device/spiral, Implan/susuk, dan Metode Operasi Pria (vasektomi), dan alat kontrasepsi dengan Metode Kontrasepsi Jangka Pendek (nonMKJP) seperti Suntik, Pil, dan Kondom. Perbedaan tersebut karena keadaan setiap individu berbeda-beda secara fisik, psikis maupun biologis.Karena perbedaan kondisi tersebut menjadikan keinginan terhadap kontrasepsi yang akan digunakan juga berbeda.

Ada beberapa faktor yang mendorong ibu-ibu Pasangan Usia Subur dalam menggunakan alat kontrasepsi/KB dengan memilih Metode Kontrasepsi Jangka Panjang (MKJP) dan dengan Metode Kontrasepsi Jangka Penedek (nonMKJP). Ibu-ibu Pasangan Usia Subur pada umumnya berminat menggunakan alat kontrasepsi/KB dengan alasan untuk menunda kehamilan dengan kurun waktu tertentu, namun ada juga ibu-ibu PUS yang menggunakan alat kontrasepsi/KB jenis tertentu untuk menghentikan kehamilan secara permanen, tetapi secara tidak langsung dengan keikutsertaan ibu-ibu PUS menjadi akseptor KB dapat menekan angka kelahiran yang menjadi permasalahan penduduk sekarang ini. Di Kelurahan Anggalomelai ada dua metode yang digunakaan oleh ibu-ibu PUS yang terbagi menjadi enam jenis alat kontrasepsi yaitu Metode Operasi Wanita (tubektomi), Intra Uterine Device (spiral), Implan, Suntik, Kondom dan Pil.

Berdasarkan hasil penelitian terhadap responden yang menggunakan kontrasepsi dengan Metode Kontrasepsi Jangka Panjang yang diwawancarai, peneliti menemukan bahwa ketertarikan ibuibu Pasangan Usia Subur terhadap alat kontrasepsi dengan metode jangka panjang karena efektifitas yang diberikan alat kontrasepsi ini untuk mencegah kehamilan lebih baik dan efektif terhadap akseptor baik dengan tujuan untuk menunda kehamilan sementara ataupun menghentikan kehamilan secara permanen sehinggaa kseptor tidak perlu khawatir untuk mengontrol $\mathrm{KB}$ yang digunakan setiap saat.

Selain itu perasaan nyaman dan cocok yang dirasakan pengguna kontrasepsi karena manfaat untuk mencegah kehamilan serta adanya manfaat lain yang dirasakan oleh akseptor sedangkan untuk efek samping untuk KB tertentu seperti Metode Operasi Wanita tidak dirasakan selama penggunaan $\mathrm{KB}$, tetapi untuk $\mathrm{KB}$ implan dan Intra Uterine Device mempunyai efek samping yang negatif seperti meningkatnya berat badan, sering terasa sakit pada bagian tubuh yang menjadi tempat pemasangan alat kontrasepsi/KB. Sedangkan berkaitan dengan pembiayaan untuk penggunaan MKJP tidak menjadi masalah bagi para akseptor karena hampir seluruhnya ditanggung oleh pemerintah. Keikutsertaan suami dalam pengambilan keputusan serta 
dengan memberikan dukungan terhadap istri dalam memilih alat kontrasepsi yang digunakan membuat istri selalu merasa nyaman, dan juga ketersediaan alat kontrasepsi di Puskesmas membuat ibu-ibu tidak merasa takut untuk memasang dan mengontrol $\mathrm{KB}$ yang digunakan sehingga selama pemakaian akseptor selalu merasa aman.

Berdasarkan hasil penelitian terhadap responden yang menggunakan alat kontrasepsi dengan Metode Kontrasepsi Jangka Pendek (non-MKJP) yang diwawancarai, peneliti menemukan bahwa ketertarikan ibu-ibu Pasangan Usia Subur di Kelurahan Anggalomelai terhadap KB non-MKJP bukan karena kefektifan dalam menunda kehamilan, tetapi Pasangan Usia Subur yang menggunakan metode non-MKJP ini hanya ingin mengatur jarak anak sekaligus mengontrol jumlah anak, perasaan takut ibu-ibu untuk menggunakan $\mathrm{KB}$ dengan metode jangka panjang juga menjadi faktor pendorong yang kuat kepada calon akseptor untuk tidak menggunakan metode jangka panjang, selain itukarena tidak cocoknya ibu-ibu Pasangan Usia Subur terhadap alat kontrasepsi jangka panajang. Akseptor non-MKJP merasakan perasaan nyaman dan cocok selama penggunaan meskipun ibu-ibu mengetahui kontrasepsi dengan metode jangka panjang yang paling efektif dan efisien untuk mencegah kehamilan tetapi ibuibu tetap memilih dan menggunakan kontrasepsi dengan metode nonMKJP. Hal yang paling mendorong keinginan ibu-ibu menggunakan KB ini karena efek samping yang merugikan hampir tidak dirasakan oleh pengguna kontrasepsi ini, meskipun harus selalu dikontrol tidak menurunkan minat ibu-ibu untuk memilih metode non-MKJP sebagai alat kontrasepsi/KB yang akan digunakan.

\section{KESIMPULAN}

Berdasarkan hasil penelitian dan pembahasan, peneliti mengambil kesimpulan yaitu:

1. Minat Pasangan Usia Subur pengguna kontrasepsidi Kelurahan Anggalomelai dalam menggunakan alat kontrasepsi/KB dengan Metode Kontrasepsi Jangka Panjang (MKJP) seperti implan, Intra Uterine Device/spiral dan Metode Operasi Wanita/ tubektomi sebanyak (14.79\%) ketertarikan terhadap metode ini karena keefektifan, perasaan nyaman dan cocok dirasakan akseptor, manfaat lain yang dirasakan akseptor serta dukungan dari luar.

2. Minat Pasangan Usia Subur pengguna kontrasepsi di Kelurahan Anggalomelai dalam menggunakan alat kontrasepsi/KB dengan metode non-MKJP seperti suntik, kondom dan pil sebanyak $(56.21 \%)$ ketertarikan terhadap metode ini karena perasaan takut PUS untuk memasang $\mathrm{KB}$ dengan metode MKJP, perasaan nyaman dan cocok, kurangnya efek samping yang negatif, serta pelayanan kesehatan yang baik (Puskesmas).

\section{DAFTAR PUSTAKA}

Augusty, Ferdinand. 2006. Metode Penelitian Manajemen.

Semarang: Universitas Diponegoro.

Bimo Walgito. Pengantar Psikologi Umum, diterbitkan oleh Yayasan Penerbitan Fakultas Psikologi UGM, Yogyakarta. 
Jurnal Penelitian Pendidikan Geografi Volume 4 No. 1 Januari 2019

BKKBN. 2006. Konversi Peserta Keluarga Berencana Menurut Jenis Kontrasepsi. Tersedia dari: http://www.bkkbn.go.id. Diakses pada tanggal 22 September 2014.

BKKBN. 2009. Pedoman pelayanan KB dalam jaminan kesehatan masyarakat. Jakarta: BKKBN

BKKBN. 2012. Pelayanan Kontrasepsi. Jakarta: BKKBN.

BKKBN. 2012, Pasangan Usia Subur, Prov. Sultra.

Djaali. 2013 :Psikologi Pendidikan, Jakarta: PT Bumi Aksara.

Darmawati. 2016. Faktor-faktor yang mempengaruhi Wanita Usia Subur memilih kontrasepsi suntik di Provinsi Banda Aceh.. Jurnal Penelitian Bidang Keilmuan Keperawatan Maternitas dan Anak volume. 2 No.3 Januari 2016. Halaman 5

Maimunah, S. 2005. Kamus Istilah Kebidanan. Jakarta: EGC.

\begin{tabular}{llr} 
Pokja & \multicolumn{1}{c}{ BKKBN } & Kelurahan \\
& Anggalomelai, & 2017. \\
& Pengguna & Kontrasepsi. \\
& Kendari &
\end{tabular}

Pokja Sanitasi Kota Kendari, Hasil Pengolahan Data Kota Kendari dalam angka 2011, BPS
Profil Puskesmas Abeli, 2014. Profil Puskesmas Abeli Kota Kendari.

Sukardi. 2010. Metodologi Penelitian Pendidikan. Jakarta: PT. Bumi Aksara.

Wiknjosastro, H. Ilmu Kebidanan. Jakarta: Yayasan Bina Pustaka 